\title{
Compression Behavior of a Biocompatible We54 Alloy Reinforced by SiC
}

\author{
Marcello Cabibbo* \\ Associate Professor of Metallurgy, Department of Industrial Engineering and Mathematics, Marche Polytechnic University, Italy
}

*Corresponding author: Marcello Cabibbo, Associate Professor of Metallurgy, Department of Industrial Engineering and Mathematics, Member of AIM "Phisical Metallurgy and Materials Science, Member of CSGI (Firenze) - Advisor of ICARUS-FET OPEN, National University Councilor of the Italian Ministry of University and Research, Marche Polytechnic University, Via Brecce Bianche, 1260131 - Ancona, Italy

\section{ARTICLE INFO}

Received: February 15, 2020

Published: 䛧 February 25, 2020

Citation: Marcello Cabibbo. Compression Behavior of a Biocompatible We54 Alloy Reinforced by SiC. Biomed J Sci \& Tech Res 26(1)-2020. BJSTR. MS.ID.004281.

Keywords: Biocompatible Mg-based Alloys; Metal Matrix Composite; Mechanical Properties; Strengthening Model; TEM

Abbreviations: MMCs: Metal Matrix Composites; TEM: Transmission Electron Microscopy; SAEDP: Selected-Area Diffraction Pattern; HCP: Hexagonal ClosedPacked; OM: Optical Microscopy

\section{ABSTRACT}

Magnesium based bio-composites and bio-alloys are used in biomedical applications such as bone fixation, cardiovascular stents, hip joints, screws/pins, and dental implants. Thence, the mechanical properties and corrosion behavior of magnesium-based biocomposites and alloys are of primary importance. In the last three decades, these properties were addressed to bust the development of modern Mg-based bio-composites for biomedical applications. Metallic and ceramic reinforcements such as $\mathrm{Ti}, \mathrm{Zn}, \mathrm{TiO}_{2}$, $\mathrm{MgO}, \mathrm{ZnO}, \mathrm{ZrO}_{2}, \mathrm{TiB}_{2}, \mathrm{Al}_{2} \mathrm{O}_{3}$, and $\mathrm{SiC}$ are known to be bioactive and bioinert. These, in turns, yield extra mechanical properties respect to the parent magnesium alloys with no reinforcements. Among the different technological and metallurgical processes of making such class of alloys, the most bio-compatible viable ones are powder metallurgy, melt deposition, and squeeze casting. In the present work, the microstructure and mechanical properties of WE54+15vol.\%SiC under various compression temperature conditions were investigated by electron microscopy. Microstructure inspections revealed the formation of stable cuboid secondary phase particles, and lamellae and irregular-shaped intermetallic phases. A microstructure-based strengthening model was proposed and compared to the experimentally obtained compression stress carried out at temperatures ranging 50 -to- $300{ }^{\circ} \mathrm{C}$. The most effective strengthening term was found to be the one coming from the refined grain structure. A further important strengthening contribution was constituted by the secondary phase particle precipitation within the Mg-matrix.

\section{Short Communication}

Mg-RE (WE) alloys have driven much interest as biomedical applications due to their outstanding high strength at both room temperature and high temperatures, excellent precipitation hardening and good biocompatibility [1-3]. With this respect, commercial alloys such the WE43 and WE54 have been widely used in various structural and biomedical applications due to their good balance on performance and cost. This interest favored a number of investigations on the mechanical properties [4-6], deformation behavior $[7,8]$, precipitation sequence $[9,10]$ of the WE series alloys. Mg-Gd-based alloys with some $\mathrm{Y}$ or $\mathrm{Nd}$ addition exhibited remarkable aging-hardening response and good ductility even after T6 treatment [11]. With this respect, Wang, et al. [4] reported that over $2 \mathrm{wt} \% \mathrm{Gd}$ additions significantly improved the ductility of the as-cast Mg-5Y-3Nd-0.6Zr alloy. Many researchers reported formation of particle, namely cuboid-shaped phases $\mathrm{Mg}_{24} \mathrm{RE}_{5}$ and $\mathrm{Mg}_{5} \mathrm{RE}$ ([12] to cite but one).

The biodegradable metallic materials can be divided into three categories, such as pure metals, alloys, and composites. Commercially available AZ91D Mg alloy is considered the most suitable bio-engineering magnesium alloy, and it has been so far deeply investigated in vivo and vitro environments. On the other hand, composite materials must possess the highest level of mechanical strength, corrosion resistance and biocompatibility to be qualified as a biomaterial implant. Ceramic-based implants were also developed due to their better mechanical performance, lack of an inflammation reaction, and optimum degradation rate. However, 
bio-absorbable ceramics also have fast degradation rates compared to non-absorbable ceramics. Mg-based bio-alloys are considered to absorb within the human body at an appropriate resorption rate, but they also have a problem of a fast degradation rate during tissue remodelling, which limits their applications in clinical fields [13]. For this reason, Mg-based alloys are still considered to be a good choice in the fields of tissue engineering, orthopaedics and cardiovascular stents because of their suitable mechanical properties, reasonable biodegradation and lower toxicity [13].

Researchers have developed Mg-based bio micro-composites and bio nanocomposites to achieve the desired mechanical properties, optimized corrosion resistance, minimum cytotoxicity, and high biocompatibility [14-21]. Numerous opportunities and challenges still exist in developing Mg-based biodegradable composites and alloys for biomedical applications. In this sense, Mg-RE alloys (such as the WE series) provide better mechanical properties and corrosion resistance at both room and high temperatures [22]. Considerable improvement of the mechanical properties can also be achieved by reinforcement with ceramic particles or fibres. Metal matrix composites (MMCs) provide a substantial increase in strength and stiffness as well as creep resistance. The ductility of composites is significantly reduced as compared to unreinforced alloys. Bio-composites have been developed and used in tissue engineering, drug delivery, dentistry and bone implants because of their high performance. However, their low stiffness, poor mechanical properties, and inflammation issues during the implantation period have limited their use in the biomedical field [13]. The composite magnesium alloys usually contain at least two components, which are known as matrix and reinforcement. All the components of the composite must be biocompatible and nontoxic in any physiological environment.

The composite material allows the combination of matrix and reinforcement properties such as sufficiently high mechanical properties (tensile strength, elastic modulus, yield strength, compression strength), corrosion resistance and biocompatibility. Thence, selection of matrix component and reinforcement component are very critical to obtain the desired properties $[23,24]$. In the present work a WE54 alloy added with 15\%vol. SiC was tested by compression at high temperatures. Microstructure evolution was inspected by electron microscopy (TEM). The work presents a microstructure based strengthening model that was compared to the experimental compression tests carried out at temperatures ranging 50 -to- $300^{\circ} \mathrm{C}$.

\section{Experimental Procedure}

The material used in this study was a WE54 magnesium matrix composite. Commercial WE54 (Mg-5wt.\%Y-4wt.\%RE, mainly Nd) alloy was reinforced by $15 \mathrm{vol} . \%$ silicon carbide particles. Composite was prepared by squeeze casting technique. Compression tests were carried out at temperatures between room temperature and $300^{\circ} \mathrm{C}$ using an INSTRON testing machine. Cylindrical specimens of
$8 \mathrm{~mm}$ in diameter and $12 \mathrm{~mm}$ long were deformed at an initial strain rate of $2.8 \cdot 10^{-4} \mathrm{~s}^{-1}$. The microstructure was inspected by optical microscopy (OM) and by transmission electron microscopy (TEM). Thin foils for TEM were mechanically thinned down to $\sim 100$ $\mu \mathrm{m}$, punched, and then dimpled to a thickness of $\sim 20 \mu \mathrm{m}$ at the centre of the 3-mm disk. This was furthermore thinned to electron transparency using a precision ion polishing system (Gatan ${ }^{\mathrm{TM}}$ PIPS) with an initial tilt angle of $8^{\circ}$, followed by a running angle of $3^{\circ}$, at voltage of $4.5 \mathrm{~V}$ and cooled by liquid nitrogen. A Philips ${ }^{\mathrm{TM}} \mathrm{CM} 20^{\circledR}$ working at $200 \mathrm{kV}$ and equipped with a double tilt specimen holder was used. Detected secondary phase particles were identified by selected-area diffraction pattern (SAEDP).

\section{Results and Discussion}

\section{Microstructure and Mechanical Properties}

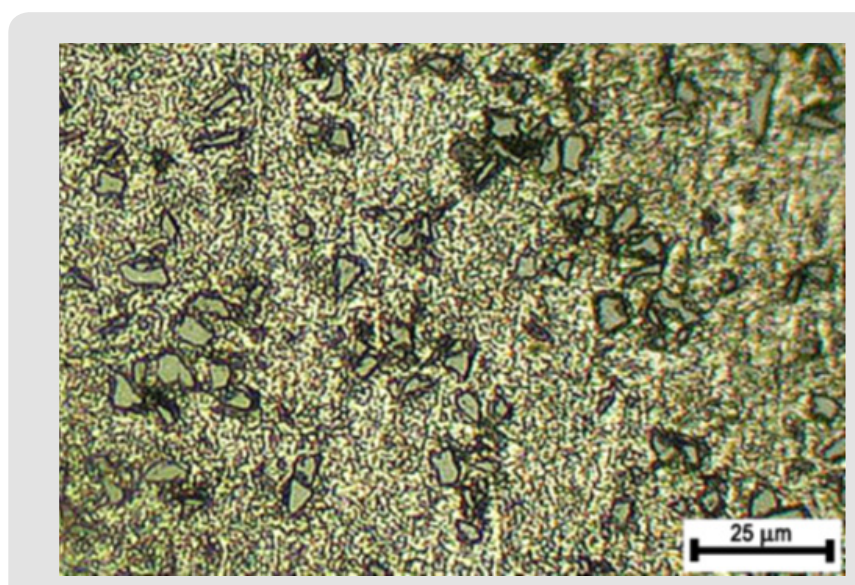

Figure 1: Microstructure of the as-produced, undeformed WE54-15\%vol.SiC composite.

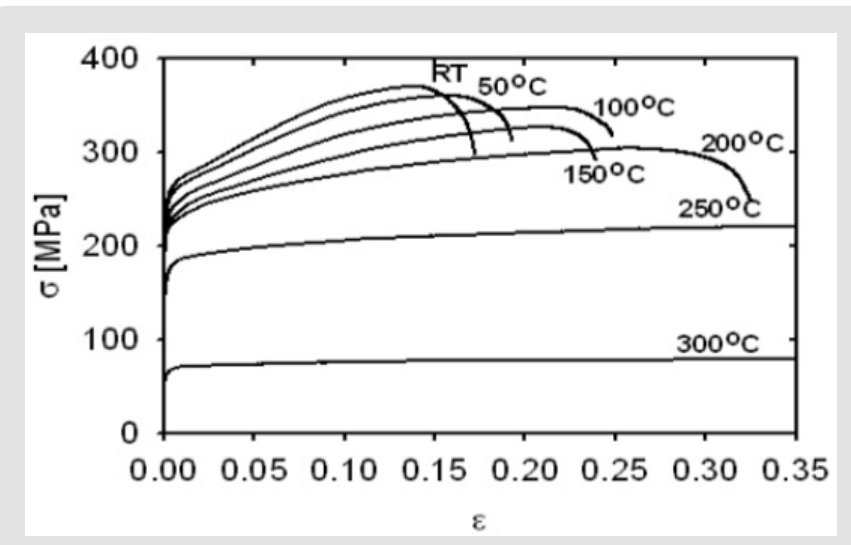

Figure 2: True stress-strain curves of the WE54 composite at different compression test temperatures (roomtemperature, 50, 100, 150, 200, 250, and $300^{\circ} \mathrm{C}$ ).

The microstructure of the composite is reported in (Figure 1). The SiC particles are not uniformly distributed in the matrix as they mostly tend to randomly cluster. The compressive true stress-strain curves at strain rate of $2.78 \times 10^{-4} \mathrm{~s}^{-1}$ and different temperatures are shown in (Figure 2). The temperature dependences of the characteristic stresses, the yield stress $\sigma_{02}$ and the maximum stress $\sigma_{M}$, are shown in (Figure 3). It appears a clear influence of the 
test temperature on the resulting alloy strain hardening, at a test temperature beyond $200^{\circ} \mathrm{C}$, as the compressive flow stress started to decrease with the temperature. In other words, the compression strength of the WE54 SiC reinforced alloy did not changed from room temperature to $200^{\circ} \mathrm{C}$. This ultimately means that the compression behaviour of the present alloy is stable for the human body temperatures and for the possible local mechanical processes of working heating and cooling prior implantation. This interesting alloy mechanical response was accounted from a microstructure viewpoint by a systematic microstructure inspection carried out by electron microscopy (TEM).

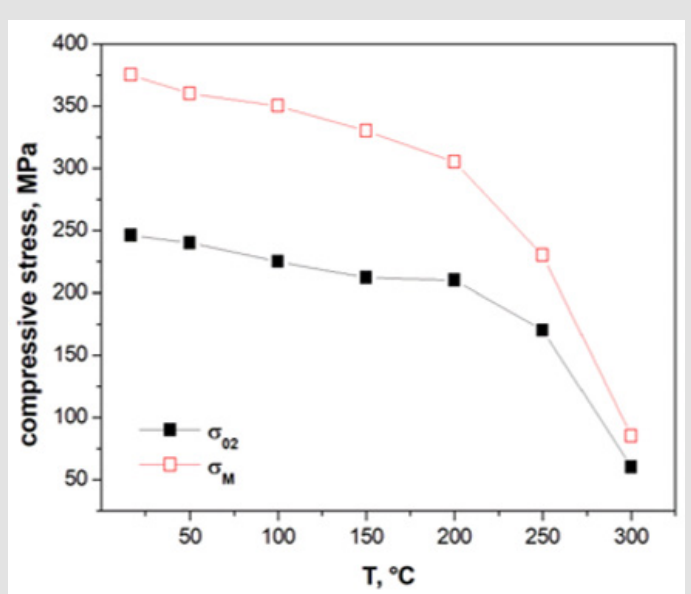

Figure 3: Temperature dependences of the alloy strength, from room temperature $\left(17^{\circ} \mathrm{C}\right)$ to the maximum test temperature of $300^{\circ} \mathrm{C}$.

(Figure 4) reports representative TEM micrographs of the alloy microstructure at room temperature (Figure $4 \mathrm{a}$ ), after compression test at $50^{\circ} \mathrm{C}$ (Figure $4 \mathrm{~b}$ ), $150^{\circ}$ (Figure $4 \mathrm{c}$ ), and $300^{\circ} \mathrm{C}$ (Figure $4 \mathrm{~d}$ ).
It appeared that the microstructure remained stable up to $200^{\circ} \mathrm{C}$, being quite like the one observed at room temperature (that is in the as-produced condition). Yet, the microstructure after the compression tests at $300^{\circ} \mathrm{C}$ clearly revealed a significant grain coarsening and secondary phase deterioration, that is coarsening of the reinforcing secondary phase particles. In addition, at $300^{\circ} \mathrm{C}$ compression test, most of the coarse secondary phase particles tend to align almost continuously at grain boundaries. This indeed correspond to a weakening morphology for the intergranular particles that can led to mechanical failure by grain decohesion. This microstructure degradation with compression temperature is ultimately believed to drive the corresponding mechanical failure of the present WE54-SiC alloy.

The microstructure inspections revealed the twin formation within the magnesium matrix. These were of nanometric scale and were found to be quite narrow and lying parallel to each other (Figure 5). Anyhow, nano-twins were detected only at testing temperature above $200^{\circ} \mathrm{C}$. The important role of twinning in the deformation of hexagonal closed-packed (hcp) lattice alloys is well known. On the other hand, dislocation density plays important role in hardening mechanism in composite. With addition of the reinforcing phase, the geometrically necessary dislocations are generated to accommodate the mismatch of plastic deformation in the matrix. New dislocations arise directly in the production process due to the solidification process during preparation of the composite. A higher dislocation density in the composite material induces a higher level of internal stress. The detected higher matrix dislocation density as well as the reinforcement/matrix interfaces can provide high diffusivity paths in the composite alloy. Significant amount of dislocations was generated during compressive deformation.

Figure 1

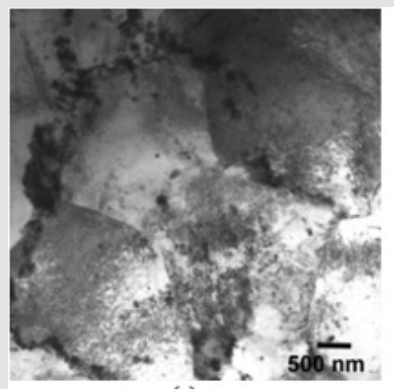

(a)

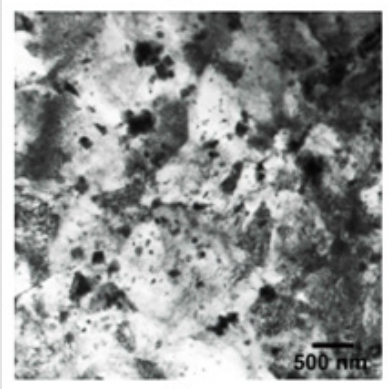

(c)

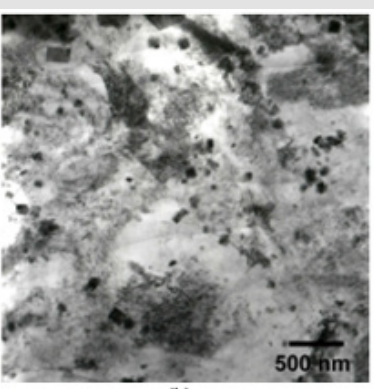

(b)

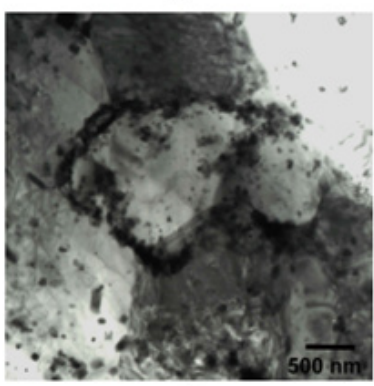

(d)

Figure 4: Representative TEM micrographs showing the microstructure at room temperature (as-produced condition),

a) after compression test at $50^{\circ} \mathrm{C}$, b) $150{ }^{\circ} \mathrm{C}$, c) at $300^{\circ} \mathrm{C}$, d) $300^{\circ} \mathrm{C}$. 


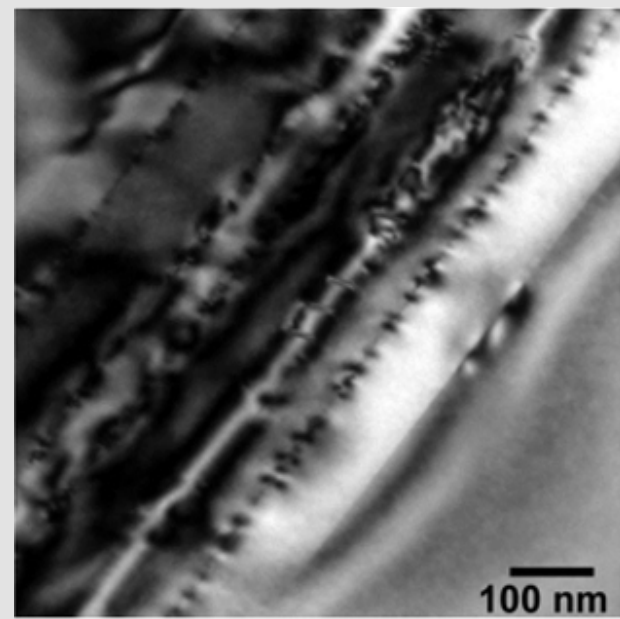

(a)

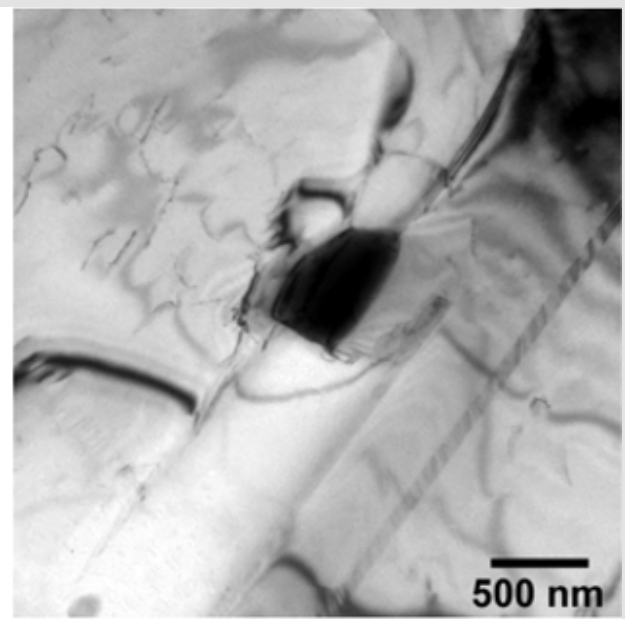

(b)

Figure 5: Representative TEM micrographs showing the formation of twinning after compression test

a) at $200^{\circ} \mathrm{C}$,

b) and after compression test at $300^{\circ} \mathrm{C}$.

Based on the quantitative evaluation of all the strengthening features appeared in the alloy microstructure a strengthening model was proposed. The major microstructure features contributing to the alloy strength are grain-structure through HallPetch mechanism of strengthening, twinning formation, secondary phase formation and eventual coarsening, composite model of strengthening given by the $\mathrm{SiC}$ particles. This microstructure-based alloy strengthening model is reported in the following.

\section{Microstructure-Base Alloy Strengthening Model}

Grain Size Strength (Hall-Petch): The strengthening contribution given by the grained structure of the magnesium matrix is expressed by the Hall-Petch relationship, which relates the alloy stress, $\Delta \sigma_{H P}$, to the mean grain size, $D_{g}$, by Eq. (1):

$$
\Delta \sigma_{H P}=K_{H P} \cdot\left(D_{g}\right)^{-0.5}
$$

where $K_{H P}=0.28 \mathrm{MPa} \cdot \mathrm{m}^{1 / 2}$ is the Hall-Petch constant [25].

This contribution varied significantly with the compression test temperature as the mean grain size increased to one-order of magnitude at the maximum test temperature of $300^{\circ} \mathrm{C}$. In fact, the mean grain size varied from the minimum value obtained at the undeformed experimental condition (as-prepared), where $D_{g}=2.8 \pm 0.6 \mu \mathrm{m}$, up to $D_{g}=4.3 \pm 0.7 \mu \mathrm{m}, D_{g}=6.9 \pm 0.7 \mu \mathrm{m}, D_{g}=$ $33 \pm 1 \mu \mathrm{m}$, after compression at 50,150 , and $300^{\circ} \mathrm{C}$, respectively. These measured mean grain sizes corresponded to a Hall-Petch grain strengthening contribution of $\Delta \sigma_{H P}=165 \pm 15 \mathrm{MPa}$, for the undeformed sample, and $\Delta \sigma_{H P}=135 \pm 15 \mathrm{MPa}, \Delta \sigma_{H P}=110 \pm 10$ $\mathrm{MPa}, \Delta \sigma_{H P}=50 \pm 10 \mathrm{MPa}$, after compression at 50,150 , and $300^{\circ} \mathrm{C}$, respectively. That is, a drastic reduction of the alloy strengthening contribution, which more than halved, occurred after compression at $300^{\circ} \mathrm{C}$, respect to the strengthening contribution yield by the grained structure after compression at $150^{\circ} \mathrm{C}$.

Twinning: Twin boundaries, $\sigma_{T}$, was calculated by a Hall-Petch type relationship as follows, Eq. (2) [26]:

$$
\Delta \sigma_{T}=V_{V}^{T \text { wins } .}\left[K_{T B} \cdot\left(\lambda_{T B}\right)^{-0.5}\right]
$$

Where $V_{v}^{\text {Twins }}$ is the measured volume fraction of the twins, $k_{T B}$ $=35 \mathrm{MPa} \cdot \mu \mathrm{m}^{1 / 2}$ is a Hall-Petch type constant, $\lambda_{T B}$ is the average twin boundary spacing. Twins were detected essentially after compression at $200^{\circ} \mathrm{C}$, and not for lower testing temperatures nor in the as-prepared condition. Thus, this contribution only holds for the conditions of compression at $300^{\circ} \mathrm{C}$ (Figure 5). Anyhow, the volume fractions of the detected twins were quite low, being $V_{v}^{\text {Twins }}$ $=2-3$ vol. $\%$. The mean twin spacing was measured as $\lambda_{T B}=22$-to$30 \mathrm{~nm}$. Thus, the twin strengthening contribution accounted for a quite low value ranging $\Delta \sigma_{T}=4-7 \mathrm{MPa}$. This make the twinning contribution essentially irrelevant.

Secondary Phase Particles: The strength given by the secondary phase particles is modelled by the Orowan mechanism. That is, the precipitation hardening is an effective strengthening factor not only at room temperature but also at higher temperatures, even although the secondary phase particles started to coarsen with compressive temperature. If these particles are within 50-80 nm in equivalent diameter these act as impenetrable particles for the sliding dislocations. Thence, gliding dislocations bows out between consecutive particles bypassing and leaving a loop around them to proceed in their sliding motion. This strengthening mechanism can be modelled by Eq. (3) $[27,28]$ : 


$$
\Delta \sigma_{\text {orowan }}=\frac{T^{\prime} E b}{4 \pi(1-v)(1+v) \lambda}\left[\ln \left(\frac{\bar{d}}{b}\right)+B\right]
$$

where $B=0.6$ for screw dislocations and 0.7 for edge dislocations, $T^{\prime}=6.5$ is the Taylor factor for $\mathrm{Mg}, E=44.4 \mathrm{GPa}$ is the magnesium Young's modulus, $b$ is the Burgers vector that for $\mathrm{Mg}$ is $0.32 \mathrm{~nm}, v=0.27$ is the Poisson's ratio, $\lambda$ represents the average interparticle spacing, which based on ASTM E112 stereology methods $\lambda=\left[1.25 /\left(d / N_{V}\right)-\pi d / 4\right]$, with $N_{V}$ the particle volume density and $d$ the mean particle equivalent diameter. This latter was quantitatively evaluated by TEM inspections. It resulted that the particle mean diameter, $d$, increased significantly form the asproduced, undeformed condition, where $d=50 \pm 5 \mathrm{~nm}$, to $d=90 \pm$ $5 \mathrm{~nm}$, after compression at $50^{\circ} \mathrm{C}, d=125 \pm 5 \mathrm{~nm}$, after compression at $150^{\circ} \mathrm{C}$, and $d=240 \pm 20 \mathrm{~nm}$, after the maximum test compression temperature of $300^{\circ} \mathrm{C}$. This strengthening contribution accounted for $\Delta \sigma_{\text {orowan }}=70 \pm 5 \mathrm{MPa}$, for the undeformed condition, and to $\Delta \sigma_{\text {orowan }}=60 \pm 5 \mathrm{MPa}, \Delta \sigma_{\text {orowan }}=45 \pm 5 \mathrm{MPa}$, and $\Delta \sigma_{\text {orowan }}=25 \pm 5$ $\mathrm{MPa}$, after compression at 50,150 , and $300^{\circ} \mathrm{C}$, respectively.

SiC Particle Composite Strength Contribution: According to the shear-lag model proposed by Nardone and Prewo in [29], the composite particles do contribute to alloy reinforcement carrying a fraction of the load from the matrix. This alloy strengthening contribution strongly depends on the shape and morphology of the particles; it specifically depends on the particle aspect ratio [30]. Thus, the proposed relationship is (Eq. (4a)):

$$
\Delta \sigma_{L T}=V_{V}^{S i C}\left[1+\frac{A(L+t)}{4 L}\right] \sigma_{0}+\left(1-V_{V}^{S i C}\right) \sigma_{0}
$$

where $\sigma_{0}$ is the unreinforced matrix yield stress, $V_{V}^{S i c}$ the Sic particle volume fraction, $L$ the particle size facing the load direction, $t$ the mean particle thickness, $A=L / t$ the particle aspect ratio. The Sic volume fraction, $V_{V}^{S i C}$, was determined using areal analysis $\left(A_{A}\right)$ stereology method (ASTM EN-112). For equiaxed particles, or alternatively particles with $2 \mathrm{D}$-shape close to circle, as in the present case, the Eq. (4a) reduces to Eq. (4b):

$$
\Delta \sigma_{L T}=\sigma_{L T}-\sigma_{0}=0.5 V_{V}^{S i C . \sigma_{0}}
$$

A further strengthening mechanism acting in the composite WE54 alloy refers to the different thermal expansion coefficients (CTE) between the SiC particles and the magnesium matrix. This induces a dislocation density increment with the applied stress, yielding an additional strengthening contribution to the alloy. The amount of the thermal stress induced by the presence of the reinforcement depends upon the particle volume fraction, morphology, and size, and on the effective temperature change. Upon high-temperature compression, the relatively large thermal expansion coefficient between the matrix and the SiC particles creates a misfit strain at the SiC-Mg interface. Thermal stress can be partially released by the dislocation generation and accumulation in the surroundings of the reinforcement surfaces. Thus, according to [31-33] the induced extra dislocation density can be calculated as Eq. (5a):

$$
\rho_{T}=\frac{c \varepsilon}{b} \frac{V_{V}^{S i C}}{\left(1-V_{V}^{S i C}\right)} \frac{1}{t^{\prime}}=\frac{c V_{V}^{S i C} \Delta \alpha \Delta T}{b\left(1-V_{V}^{S i C}\right) t^{\prime}} \quad \text { Eq. (5a) }
$$

where $C=12$ for equiaxed particles, $\varepsilon=\Delta \alpha \cdot \Delta T$ is the misfit strain, $\Delta T$ is the temperature variation, $\Delta \alpha=21 \cdot 10^{-6} \mathrm{~K}^{-1}$ is the difference between matrix and Sic thermal expansion, $V_{V}^{S i C}$ the particle volume fraction, and $t^{\prime}$ the minimum size of the SiC particles. The thermally generated dislocation density yields a strengthening contribution of (Eq. (5b)):

$$
\Delta \sigma_{T}=\alpha_{1} T^{\prime} G b\left(\rho_{T}\right)^{0.5} \quad \text { Eq. (5b) }
$$

with $\alpha_{1}=0.35$, and $G=17480 \mathrm{MPa}$ is the shear modulus of Mg.

Since the average residual stress generated by the thermal expansion is of tension nature, it is a negative contribution to the strengthening to the magnesium composite alloy [34]. The different nature of the ceramic Sic particles respect to the metallic magnesium matrix induces geometrically necessary dislocations resulting in an additional strengthening contribution to the alloy. The resulting matrix-to-particle misfit depends on the reinforcement size and morphology [35]. The density of the geometrical necessary dislocations is given by Eq. (6a) [33,34]:

$$
\rho_{G E O}=8 \frac{V_{V}^{S i C \cdot \varepsilon_{p}}}{b t^{\prime}} \quad \text { Eq. (6a) }
$$

where $\varepsilon_{p}=0.28$ is the plastic strain. The corresponding strengthening contribution is thus (Eq. (6b)):

$$
\Delta \sigma_{\text {GEOM }}=\alpha_{1} T^{\prime} G b\left(\rho_{\text {GEOM }}\right)^{0.5} \quad \text { Eq. (6b) }
$$

According to the statistical evaluations of all the meaningful microstructure features appearing in the Eqs. (4)-to-(6), the $\mathrm{SiC}$ strengthening contribution was evaluated as $\Delta \sigma_{\text {Sic }}=57 \pm 3 \mathrm{MPa}$, for the undeformed condition, $\Delta \sigma_{\text {SiC }}=63 \pm 3 \mathrm{MPa}, \Delta \sigma_{\text {SiC }}=115 \pm 5$ $\mathrm{MPa}, \Delta \sigma_{\text {SiC }}=25 \pm 5 \mathrm{MPa}$, after compression at 50,150 , and $300^{\circ} \mathrm{C}$, respectively. That is, the $\mathrm{SiC}$ strengthening contribution tended to increase steadily with the compression temperature up to $150^{\circ} \mathrm{C}$, to drastically reduce, and then degrading, at $300^{\circ} \mathrm{C}$.

Strengthening Term Combination: According to Leidholt [36] the stress contributions acting uniformly throughout the matrix are superimposed linearly, whereas mechanisms of similar strengthening ability, which act unevenly throughout the matrix, are most suitably combined as the square root of the sum of the squares $[37,38]$.

Thence the following model is here proposed:

$$
\sigma_{\text {model }}=\sigma_{0}+\left(\left(\Delta \sigma_{H P}+\Delta \sigma_{T}+\Delta \sigma_{\text {orowan }}\right)^{2}+\Delta \sigma_{S i C^{2}}\right)^{0.5}
$$

(Table 1) reports the obtained results by applying the Eq. (7) to the as-prepared alloy, and the compression tested conditions at 50 , 
150, and $300{ }^{\circ} \mathrm{C}$. The obtained agreement between the modelled strength and the experimentally measured compression strengths was of some $20 \%$ lower between the model and the measured values, except for the $300^{\circ} \mathrm{C}$ condition, where the model overestimated the experimental value by some $20 \%$. This discrepancy is likely to be attributed to a further Orowan-like strengthening contribution that was not here taken into consideration due to a lack of experimental information. On the other hand, it resulted that the observed alloy mechanical degradation occurred at compression temperature of $300^{\circ} \mathrm{C}$ was due in particular to an excess of grain size coarsening, which resulted in a strength reduction of one-third respect to the value obtained for the undeformed condition. A second microstructure factor affecting the alloy mechanical degradation occurred at $300{ }^{\circ} \mathrm{C}$ came from the significant reduction of the secondary phase strengthening contribution, and to a lower extent from the SiC strength contribution.

Table 1: Alloy strength as obtained by applying Eq. (7) to the as-prepared alloy, and the compression tested conditions at 50, 150, and $300^{\circ} \mathrm{C}$.

\begin{tabular}{|c|c|c|c|c|}
\hline $\boldsymbol{\sigma}_{\boldsymbol{o}}$ : Ultimate Strength & Undeformed & Compression at $\mathbf{5 0}^{\circ} \mathbf{C}$ & Compression at $\mathbf{1 5 0}^{\circ} \mathbf{C}$ & Compression at $\mathbf{3 0 0}^{\circ} \mathbf{C}$ \\
\hline$\sigma_{\text {exp }}, \mathrm{MPa}$ & $375 \pm 5$ & $355 \pm 5$ & $330 \pm 5$ & $85 \pm 5$ \\
\hline$\sigma_{\text {model }} \mathrm{MPa}$ & $305 \pm 15$ & $265 \pm 15$ & $270 \pm 20$ & $100 \pm 20$ \\
\hline
\end{tabular}

\section{Concluding Remarks}

WE54 Mg-RE (RE=Y, Nd, Gd, Dy) alloy-based composite was prepared by squeeze casting. Compression tests were carried out in the temperature range from room temperature up to $300^{\circ} \mathrm{C}$. The stress-strain curves showed a high degree of work hardening at the lower temperatures. The most important contributions to the alloy stress were given by the matrix small grain size and by the precipitation hardening, prior of excessive coarsening upon testing at temperatures beyond $200^{\circ} \mathrm{C}$. The reinforcing phase contributes to strengthening mainly through an increased dislocation density, i.e. by thermal and geometrical mismatch. It also resulted that at $300{ }^{\circ} \mathrm{C}$ grain size drastically increased up to one-order of magnitude respect to the undeformed condition. A mixed combination of the different strengthening terms was used to meet the yield stress obtained mechanically. Specifically, a linear sum of the evenly distributed strengthening terms in the matrix was quadratically combined to the contributions given by the presence of the $\mathrm{SiC}$ particles: $\sigma_{0}+\left(\left(\Delta \sigma_{H P}+\Delta \sigma_{T}+\Delta \sigma_{\text {orowan }}\right)^{2}+\Delta \sigma_{\text {Sic }}\right)^{0.5}$. This microstructure-based model was able to describe the microstructure factors contributing to the alloy strength at the different testing temperatures.

\section{References}

1. $\mathrm{CH}$ Ye, YF Zheng, SQ Wang, TF Xi, YD Li, et al. (2012) In vitro corrosion and biocompatibility study of phytic acid modified WE43 magnesium alloy. Appl Surf Sci 258(8): 3420-3427.

2. F Klocke, M Schwade, A Klink, A Kopp (2011) EDM machining capabilities of magnesium (Mg) alloy WE43 for medical applications. Procedia Eng 19: 190-195.

3. Y Liu, S Zheng, N Li, H Guo, Y Zheng, et al. (2016) Study on the in vitro degradation behavior of pure Mg and WE43 in human bile for 60 days for future usage in biliary. Mater Lett 179: 100-103.

4. LD Wang, CY Xing, XL Hou, YM Wu, JF Sun, et al. (2010) Microstructures and mechanical properties of as-cast Mg-5Y-3Nd-Zr-xGd ( $\mathrm{x}=0,2$ and 4 wt.\%) alloys. Mater Sci Eng A 527(7): 1891-1895.

5. YH Kang, H Yan, RS Chen (2015) Effects of heat treatment on the precipitates and mechanical properties of sand-cast Mg-4Y-2.3 Nd-1Gd0.6Zr magnesium alloy. Mater Sci Eng A 645: 361-368.

6. YH Kang, XX Wang, N Zhang, H Yan, RS Chen, et al. (2017) Effect of predeformation on microstructure and mechanical properties of WE43 magnesium alloy. Mater Sci Eng A 689: 435-445.
7. SM Zhu, JF Nie (2004) Serrated flow and tensile properties of a Mg-Y-Nd alloy. Scripta Mater. 50: 51-55.

8. N Kumar, N Dendge, R Banerjee, R Mishra (2014) Effect of microstructure on the uniaxial tensile deformation behavior of Mg-4Y-3RE alloy. Mater Sci Eng A 590: 116-131.

9. JF Nie, BC Muddle (2000) Characterization of strengthening precipitate phases in a Mg-Y-Nd alloy. Acta Mater 48(8): 1691-1703.

10. C Antion, P Donnadieu, F Perrard, A Deschamps, C Tassin, et al. (2003) Hardening precipitation in a Mg-4Y-3RE alloy. Acta Mater 51(8): 53355348.

11. Q Liu, X Ding, Y Liu, X Wei (2016) Analysis on micro-structure and mechanical properties of Mg-Gd-YNd-Zr alloy and its reinforcement mechanism. J All Comp d 690: 961-965.

12. SM He, XQ Zeng, LM Peng, X Gao, JF Nie, et al. (2007) Microstructure and strengthening mechanism of high strength Mg-10Gd-2Y-0.5Zr alloy. J All Compd 427: 316-323.

13. M Prakasam, J Locs, K Salma Ancane, D Loca, A Largeteau, et al. (2017) Biodegradable materials and metallic implantsda review. J Funct Biomater 8: 44-49.

14.S Agarwal, J Curtin, B Duffy, S Jaiswal (2016) Biodegradable magnesium alloys for orthopedic applications: A review on corrosion, biocompatibility and surface modifications. Mater Sci Eng C 68: 948963.

15. M Pogorielov, E Husak, A Solodivnik, S Zhdanov (2017) Magnesiumbased biodegradable alloys: degradation, application and alloying elements. Interv Med Appl Sci 9: 27-38.

16. J Chen, L Tan, X Yu, IP Etim, M Ibrahim, et al. (2018) Mechanical properties of magnesium alloys for medical application: A review. J Mech Behav Biomed Mater 87: 68-79.

17. BJ Luthringer, F Feyerabend, R Willumeit R€omer (2014) Magnesiumbased implants: A mini-review. Magnes Res 27: 142-154.

18. N Li, Y Zheng (2013) Novel magnesium alloys developed for biomedical application: A review. J Mater Sci Technol 29: 489-502.

19. L Tan, J Dong, J Chen, K Yang (2017) Development of magnesium alloys for biomedical applications: Structure, process to property relationship. Mater Technol 33(3): 235-243.

20. M Peron, J Torgersen, F Berto (2017) Mg and its alloys for biomedical applications: Exploring corrosion and its interplay with mechanical failure. Metals (Basel) 7: 252-261.

21. A Atrens, M Liu, NI Zainal Abidin (2011) Corrosion mechanism applicable to biodegradable magnesium implants. Mater Sci Eng B 176: 1609-1636.

22. SM He, XQ Zeng, LM Peng, X Gao, JF Nie, et al. (2006) Precipitation in a Mge10Gde3Ye0.4Zr (wt.\%) alloy during isothermal ageing at $250^{\circ} \mathrm{C}$. J All Compd 421: 309-313. 
23. F Feyerabend, J Fischer, J Holtz, F Witte, R Willumeit, et al. (2010) Evaluation of short-term effects of rare earth and other elements used in magnesium alloys on primary cells and cell lines. Acta Biomatter 6: 1834-1842.

24. X Zhang, G Yuan, L Mao, J Niu, P Fu, W Ding, et al. (2012) Effects of extrusion and heat treatment on the mechanical properties and biocorrosion behaviors of a Mg-Nd-Zn-Zr alloy. J Mech Behav Biomed Mater 7: 77-86.

25. M Mabuchi, K Higashi (1996) Strengthening mechanisms of Mg-Si alloys. Acta Mater 44: 4611-4618.

26. X Li, Y Wei, L Lu, K Lu, H Gao, et al. (2010) Dislocation nucleation governed softening and maximum strength in nano-twinned metals. Nature 464: 877-880.

27. RO Scattergood, D Bacon (1975) The Orowan mechanism in anisotropic crystals. Philos Mag A 31: 179-198.

28. YH Yeh, H Nakashima, H Kurishita, S Goto, H Yoshinaga, et al. (1990) Threshold stress for high-temperature creep in particle strengthened Al-1.5 vol\% Be alloys. Mater Trans JIM 31: 284-292.

29. VC Nardone, KM Prewo (1986) On the strength of discontinuous silicon carbide reinforced aluminum composites. Scripta Metall 20: 43-48.

30. M Mabuchi, K Higashi (1996) Strengthening mechanisms of Mg-Si alloys. Acta Mater 11: 4611-4618.

\section{ISSN: 2574-1241}

DOI: 10.26717/BJSTR.2020.26.004281

Marcello Cabibbo. Biomed J Sci \& Tech Res

(C) This work is licensed under Creative

Submission Link: https://biomedres.us/submit-manuscript.php
31. RJ Arsenault, L Wang, CR Feng (1991) Strengthening of composites due to microstructural changes in the matrix. Acta Metall Mater 39: 47-57.

32. RJ Arsenault, M Taya (1987) Thermal residual stress in metal matrix composite. Acta Metall 35: 651-659.

33. RM Aikin, L Christodoulou (1991) The role of equiaxed particles on the yield stress of composites. Scripta Metall Mater 25: 9-14.

34. RJ Arsenault, N Shi (1986) Dislocation generation due to differences between the coefficients of thermal expansion. Mater Sci Eng 81: 175187.

35. JK Lee, YY Earmme, HI Aaronson, KC Russell (1980) Plastic relaxation of the transformation strain energy of a mis fitting spherical precipitate: Ideal plastic behavior. Metall Trans 11A: 1837-1847.

36. Lilholt N (1983) Additive strengthening, deformation of multi-phase and particle containing materials. In: Hansen N, Horsewell A, Leffers T, Liohot H (Eds.)., Roskilde, Risǿ Nat Lab, Denmark, pp. 381-386.

37. Clyne T, Whithers PJ (1993) An introduction to metal matrix composites. Cambridge: Cambridge Press.

38. Kocks UF, Argon AR, Ashby MF (1975) Thermodynamics and kinetics of slip. Prog Mater Sci 19: 1-22.

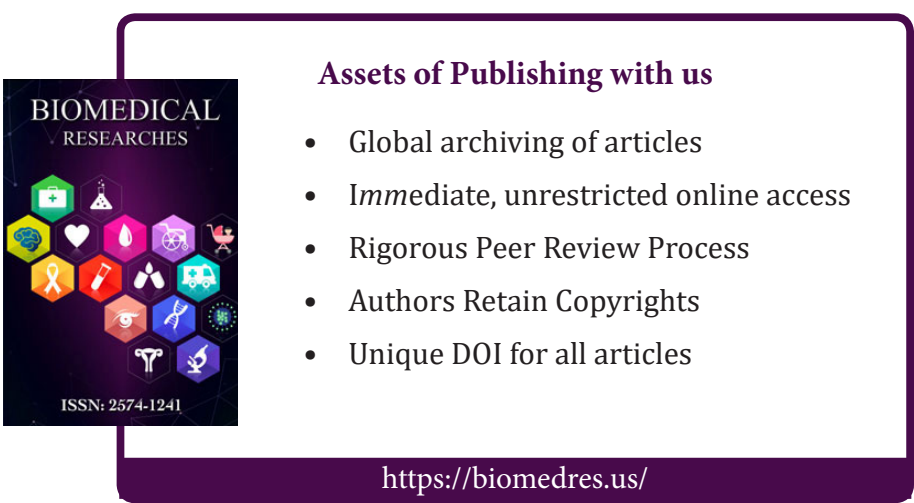

